\title{
Factors influencing eating a varied diet in old age
}

\author{
Moira Dean ${ }^{1}$, Monique M Raats ${ }^{2, *}$, Klaus G Grunert ${ }^{3}$, Margaret Lumbers $^{2}$ and \\ The Food in Later Life Team \\ 'School of Biological Sciences, Queens University Belfast, David Keir Building, Stranmillis Road, Belfast BT9 \\ 5AG, UK: ${ }^{2}$ Food, Consumer Behaviour and Health Research Centre, University of Surrey, Guildford, Surrey, \\ GU2 7XH, UK: ${ }^{3}$ MAPP - Centre for Research on Customer Relations in the Food Sector, University of Aarhus, \\ Haslegaardsvej 10, DK-82 10 Aarhus V, Denmark
}

Submitted 13 February 2008: Accepted 5 February 2009: First published online 6 April 2009

\begin{abstract}
Objective: To investigate the influences of resources and food-related goals on the variety of food choice among older people.

Design: A questionnaire-based survey in eight European countries: Poland, Portugal, United Kingdom, Germany, Sweden, Denmark, Italy and Spain.

Subjects: Participants ( $n$ 3200) were above 65 years of age and living in their own homes. The samples were quota samples, eight groups of fifty in each country, based on gender, age and living circumstances, reflecting the diversity of each of the national populations based on education, income and urbanization of living environment.

Results: Hierarchical multiple regression analysis showed that income, health status, access to a car and living arrangement affected the level of dietary variety. The perceived level of different food-related resources impacted the consumption of a varied diet over and above actual resource levels. Food-related goals contributed to variety of food intake that was not accounted for by the amount of material resources possessed or the social and other resources perceived to be possessed.

Conclusions: Older people's variety of food intake depended on material resources (e.g. monthly income, access to a car, living arrangement, physical and mental health). However, in addition to these variables, the way older people perceived other resources, such as their level of appetite, their food knowledge, their perception of the distance to the shops, access to high-quality products, having better kitchen facilities, access to good service providers and support from friends and neighbours, all contributed to how varied a diet they ate.
\end{abstract}

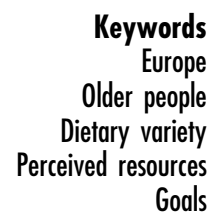

Europe

Dider people

Goals
Older people represent an increasing proportion of the population $^{(1)}$. Health or its absence in this rapidly increasing population not only affects the individuals themselves, but also has serious implications for demands on health care and other social resources. Cross-cultural studies ${ }^{(2-4)}$ examining lifestyle variables and health suggest that diet is an important predictor of survival. For elderly individuals, inadequate nutrition can increase the incidence and severity of disease, hastening loss of independence. It is thus important to understand what influences older people's food choices to help ensure healthier diets ${ }^{(5)}$.

Studies suggest that Mediterranean-style diets as well as limited intake of red meat and high cereal-fibre consumption reduce CVD and cancer in older people, suggesting that eating a diet that is high in fruits, vegetables, nuts, cereals and low in red meat is healthy ${ }^{(6-9)}$. Thus a varied diet is seen as a healthy diet, as food variety enables food component needs to be met adequately and comprehensively ${ }^{(2,10-12)}$.
The ability to choose a diet with sufficient quality and variety to meet daily nutrient needs may be adversely affected by the pathological, physiological, economic and societal factors that accompany ageing ${ }^{(13)}$. For example, gradual loss of health due to the effects of chronic diseases such as arthritis or diabetes can impair the ability to obtain, prepare and enjoy nutritious foods ${ }^{(14)}$. The decline in the ability to taste and smell may result in changes to food selection and preference, leading to changes in energy and/or nutrient intake ${ }^{(15,16)}$. This is confirmed by nutritional surveys showing a reduced variety in older people's diets ${ }^{(17)}$. In addition, Duffy et $a l^{(18)}$ found that women with impaired ability to smell not only had lower preferences for some nutritious foods and higher intakes of sweets and fats, but also had less interest in food-related activities such as cooking. However, while the decline in sensory-specific satiety may influence variety of food choice, social and environmental resources and older people's food-related goals may override the 
importance of the physiological factor in ensuring a varied and balanced diet.

Past research suggests that high level of income, good physical and mental health, mobility in terms of having access to a car and the number of social contacts are resources that may affect older people's eating habits $^{(13,18-20)}$. Lower levels of economic resources are associated with greater risk of experiencing hunger and food insufficiency ${ }^{(21,22)}$. Some research ${ }^{(23)}$ suggests that it costs more to eat healthily; thus low income restricts not just quantity but also the nutritional quality of the food purchased. Research also shows that health problems related to inadequate nutrition are more prevalent in rural areas, where transportation to and from shops is mentioned as a structural barrier to obtaining adequate food $^{(14,24,25)}$. Thus higher economic status and access to a car may be resources that may contribute to older people having a more varied diet.

Loneliness due to loss of spouse or friends can diminish the social reasons for and pleasure associated with eating ${ }^{(26,27)}$. Eating regular meals and having an adequate diet have in part been found to depend on eating with others ${ }^{(26-28)}$. However, Walker and Beauchene ${ }^{(27)}$ showed that people's number of social contacts bore no relationship to food choice. Revenson and Johnson ${ }^{(29)}$ claimed it is the dissatisfaction with available relationships rather than the number of social contacts that is a powerful indicator of loneliness and cause of reduced intake, suggesting that for social resources the perceived quality of a resource is more important than the actual level.

Studies show that knowledge-based resources such as food knowledge and cooking skills also impact on food choice $^{(30,31)}$. That is, those who think they have a good understanding of foods and feel highly skilled eat a more varied a diet than those who feel that their knowledge and skills are limited. This implies that older people's perceptions of food-related resources influence their food intake over and above actual resources.

Research has shown that the goals people have in life affect their food choice and the satisfaction they feel with their life $\mathrm{e}^{(32-35)}$. People's judgement of the healthiness of food was influenced by whether or not they had dieting as a food-related goal $^{(32)}$. Diener and Fujita ${ }^{(34)}$ showed that people tend to have goals relevant to their strongest resources and people who have the resources relevant to their goals/strivings exhibit the highest subjective wellbeing. Similar findings were observed in relation to food and older people by Dean et al. ${ }^{(35)}$.

Through testing the following hypotheses, the present study aimed to investigate the influence of resources and food-related goals on the variety of older people's food choice:

1. Income, health status, access to a car and living arrangement will affect the level of dietary variety.
2. Perceived level of different food-related resources will impact on the consumption of a varied diet over and above actual resource levels.

3. Food-related goals will contribute to variety of food intake that is not accounted for by the amount of material resources possessed or the social and other resources perceived to be possessed.

\section{Method}

A survey was conducted in eight European countries: Poland, Portugal, United Kingdom, Germany, Sweden, Denmark, Italy and Spain. Questionnaires were administered face-to-face by trained interviewers. The questionnaire was developed in English, translated and back-translated before it was piloted in each country.

\section{Sample}

Data collection took place in the autumn of 2005. In total 3200 participants (400 from each country), who were above 65 years of age and living in their own homes, were sampled using telephone recruitment from senior day centres and some snowballing by marketing companies (Table 1). The questionnaire was administered face-to-face by trained interviewers using computer-aided personal interviewing. All respondents participated at least to some degree in either procurement or preparation of food in the household. The samples were quota samples, eight groups of fifty in each country, based on gender, age ( $<75$ years $v$. $\geq 75$ years) and living circumstances (living alone $v$. living with a partner), reflecting the diversity of each of the national populations based on education, income and urbanization of living environment (urban/suburban/rural). The sample was taken from at least three geographical locations in each country. Non-response was not logged.

\section{Measures}

The selection process of resources and food-related goals potentially relevant for seniors' satisfaction with their food-related life was based on an analysis of eighty indepth interviews with seniors (ten participants from each of the above eight quota groups) in each of the eight countries. The most frequently named food-related resources and goals were collected from these qualitative data, resulting in the extraction of eleven goals (rated for importance on a 5-point scale from not important to extremely important) and twenty-two resources (assessed through agreement with the statement 'Do you agree or disagree that you have a good (resource name)?' on a 5-point scale from strongly disagree to strongly agree) which were included in the questionnaire (Table 2).

Nutritional adequacy was measured using a weekly food variety score ${ }^{(36)}$ that measures food variety according to the biological/botanical origins of the food, e.g. all 
Table 1 Characteristics of participants in the eight countries

\begin{tabular}{|c|c|c|c|c|c|c|c|c|}
\hline & Sweden & Denmark & Germany & Poland & UK & Italy & Spain & Portugal \\
\hline Number & 400 & 417 & 430 & 422 & 400 & 409 & 413 & 400 \\
\hline Men & 50 & 49 & 48 & 48 & 52 & 49 & 50 & 50 \\
\hline Women & 50 & 51 & 52 & 52 & 48 & 51 & 50 & 50 \\
\hline \multicolumn{9}{|l|}{ Living (\%) } \\
\hline Alone & 48 & 50 & 50 & 52 & 51 & 50 & 50 & 50 \\
\hline $\begin{array}{l}\text { With a partner } \\
\text { Age group }(\%)\end{array}$ & 52 & 50 & 50 & \multicolumn{4}{|c|}{ Age group (\%) } & 50 \\
\hline$<75$ years & 51 & 50 & 51 & 50 & 53 & 50 & 50 & 50 \\
\hline$\geq 75$ years & 49 & 50 & 49 & 50 & 47 & 50 & 50 & 50 \\
\hline \multicolumn{9}{|l|}{ Health status } \\
\hline Physical & $49 \cdot 3$ & $49 \cdot 0$ & $45 \cdot 0$ & $42 \cdot 0$ & $46 \cdot 4$ & $46 \cdot 7$ & $44 \cdot 1$ & $42 \cdot 9$ \\
\hline Mental & $52 \cdot 1$ & $54 \cdot 6$ & $52 \cdot 3$ & $50 \cdot 4$ & $53 \cdot 1$ & $49 \cdot 2$ & $50 \cdot 3$ & $48 \cdot 1$ \\
\hline Access to car (\%) & 59 & 71 & 63 & 38 & 63 & 66 & 33 & 33 \\
\hline Food variety score & $31 \cdot 2$ & $28 \cdot 9$ & $27 \cdot 7$ & $27 \cdot 8$ & $28 \cdot 0$ & $26 \cdot 6$ & $28 \cdot 0$ & $27 \cdot 3$ \\
\hline
\end{tabular}

citrus fruits are grouped together. Foods can be added up, with each biologically distinct food group scoring only once, no matter how often the foods within this group are eaten, but a minimum quantity of about 2 tablespoons must be consumed before it can be scored. Foods from these various sources can be scored and the total used as an indication of adequate nutrient intake. A food variety score of at least 15 over one week is generally nutritionally adequate. A score of 30 over a week or 12 in a day is considered excellent. The weekly food score has been used in different countries such as Australia, Japan and Vietnam ${ }^{(36-40)}$. As the score measures food groups rather than particular foods, this measure was chosen as it was thought to be an ideal tool to compare nutritional intake across different countries.

Further, participants' levels of actual resources were measured with respect to car availability, living arrangement, monthly income, and physical (PCS8) and mental health (MCS8) as measured by the SF-8 Health Survey ${ }^{(41)}$. Demographics (e.g. gender, age, education, weight and height) were also obtained.

\section{Results}

Correlations between the predictor variables (only $r>10.31$ are reported here) showed high positive correlations of monthly income with car availability $(r=0 \cdot 40)$, good dental health $(r=0 \cdot 29)$ and perception of a good income $(r=0.53)$ and negative correlation with the goal of keeping expenditure low $(r=-0 \cdot 40)$. Further, measured physical health (PCS8) was positively correlated with measured mental health (MCS8; $r=0 \cdot 37$ ), perception of good health $(r=0.58)$ and perceived mobility level $(r=0.53)$. In addition, measured mental health was positively correlated with perceived good health $(r=0 \cdot 41)$. As expected, those who perceived themselves to be in good health also saw themselves as having good dental health $(r=0 \cdot 30)$ and good mobility $(r=0 \cdot 41)$. Living arrangement (alone $v$. with a partner) was highly negatively correlated with sharing meals with others $(r=-0 \cdot 61)$ and with the goal of eating in the company of others $(r=-0 \cdot 35)$. In terms of perceived resource levels, cooking skills was positively correlated with food knowledge $(r=0 \cdot 43)$ and good income was positively correlated with having access to high-quality products/brands $(r=0.33)$ and negatively correlated with the goal of keeping expenditure low $(r=-0 \cdot 41)$. Moreover, the resource of having access to convenient products was positively correlated with the perceived resource level of low prices $(r=0 \cdot 31)$, access to new products $(r=0 \cdot 34)$ and access to high-quality products/ brands $(r=0 \cdot 32)$.

The influence of material resources (income, physical health, mental health, access to a car and living arrangement) on varied eating was investigated by hierarchical multiple regression analysis where the regression of the summed measure of varied eating $v$. monthly income, PCS8, MCS8, living alone/with partner and having a car was performed, in the first step. In order to see whether perceived resources could add to the prediction of varied eating, the twenty-two perceived levels of resources were added as a second step. To analyse whether people's goals contribute to their eating habits over and above the influences of perceived and actual resources, the eleven individual goals were entered into the hierarchical analysis as a third step.

\section{Actual resources and their influence on variety of diet}

Multiple regression of varied eating $v$. the five objective resource levels (adjusted $R^{2}=0 \cdot 07, F(5,1479)=22 \cdot 39$, $P<0 \cdot 001)$ revealed significant independent effects for living arrangement $(\beta=-0 \cdot 09, \quad P<0 \cdot 001)$, car availability $(\beta=-0 \cdot 10, P=0 \cdot 01)$, physical health $(\beta=0 \cdot 10$, $P<0 \cdot 001)$, mental health $(\beta=0 \cdot 07, \quad P<0 \cdot 001)$ and monthly income $(\beta=0 \cdot 09, P<0 \cdot 001)$. This suggests that those who live with a partner eat a more varied diet than those who live alone. Also, those who have access to a car have a more varied diet. In addition, mental and 
Table 2 Multiple hierarchical regression of summed eating habits $v$. perceived resources and goals among older people $(n 1484)$ from eight European countries

\begin{tabular}{|c|c|c|c|c|c|c|c|c|c|}
\hline & \multicolumn{3}{|c|}{ Step 1} & \multicolumn{3}{|c|}{ Step 2} & \multicolumn{3}{|c|}{ Step 3} \\
\hline & $B$ & SE & $\beta$ & $B$ & SE & $\beta$ & $B$ & SE & $\beta$ \\
\hline Constant & $25 \cdot 75$ & & & $10 \cdot 78$ & $2 \cdot 00$ & & $8 \cdot 67$ & $2 \cdot 12$ & \\
\hline Monthly income & 0.20 & & $0.09^{\star *}$ & $0 \cdot 10$ & 0.07 & 0.04 & $0 \cdot 15$ & 0.07 & $0.07^{*}$ \\
\hline PCS8 & 0.06 & & $0 \cdot 1^{* *}$ & 0.06 & 0.02 & $0.09^{* *}$ & 0.06 & 0.02 & $0 \cdot 10^{\star *}$ \\
\hline MCS8 & 0.05 & & $0.07^{\star}$ & 0.03 & 0.02 & 0.04 & 0.03 & 0.02 & 0.05 \\
\hline Car in household & $-1 \cdot 32$ & & $-0 \cdot 1^{\star \star \star}$ & $-1 \cdot 18$ & 0.34 & $-0.09^{\star \star}$ & $-1 \cdot 13$ & 0.34 & $-0.09^{\star \star}$ \\
\hline Living circumstance & $-1 \cdot 06$ & & $-0.08^{\star \star}$ & -0.71 & 0.39 & 0.06 & -0.63 & 0.39 & -0.05 \\
\hline \multicolumn{10}{|l|}{ Resources } \\
\hline Being in good health & & & & -0.24 & $0 \cdot 19$ & -0.04 & -0.27 & $0 \cdot 19$ & -0.04 \\
\hline A good appetite for food & & & & 0.73 & $0 \cdot 19$ & $0 \cdot 10^{\star \star \star}$ & * 0.67 & $0 \cdot 19$ & $0.09^{\star \star}$ \\
\hline Good dental health & & & & -0.04 & $0 \cdot 14$ & -0.00 & -0.09 & $0 \cdot 14$ & -0.02 \\
\hline Good cooking skills & & & & 0.02 & $0 \cdot 16$ & 0.00 & -0.22 & $0 \cdot 17$ & -0.04 \\
\hline A good general knowledge about food and nutrition & & & & $1 \cdot 35$ & $0 \cdot 19$ & $0 \cdot 2^{\star \star \star}$ & $1 \cdot 14$ & $0 \cdot 19$ & $0 \cdot 17^{\star * \star}$ \\
\hline Being able to get around on foot (mobility) & & & & $-0 \cdot 8$ & $0 \cdot 18$ & $-0 \cdot 10$ & -0.01 & $0 \cdot 18$ & -0.00 \\
\hline Ability to taste and smell well & & & & 0.24 & $0 \cdot 21$ & 0.03 & $0 \cdot 15$ & 0.21 & 0.02 \\
\hline Adequate income & & & & -0.02 & $0 \cdot 16$ & -0.00 & -0.01 & $0 \cdot 17$ & -0.00 \\
\hline Access to food at low prices & & & & $-0 \cdot 16$ & $0 \cdot 16$ & -0.03 & $-0 \cdot 18$ & $0 \cdot 16$ & -0.03 \\
\hline Access to food that is quick and easy to prepare & & & & -0.47 & $0 \cdot 17$ & $-0 \cdot 08^{\star \star}$ & -0.51 & 0.17 & $-0.08^{\star \star}$ \\
\hline $\begin{array}{l}\text { Access to good service providers, e.g. a day centre or meals } \\
\text { on wheels }\end{array}$ & & & & 0.67 & $0 \cdot 11$ & $0 \cdot 15^{\star \star \star}$ & * $0 \cdot 70$ & $0 \cdot 11$ & $0 \cdot 16^{\star \star \star}$ \\
\hline Food storage & & & & $0 \cdot 10$ & $0 \cdot 20$ & 0.01 & $0 \cdot 10$ & 0.25 & 0.01 \\
\hline Access to new and different types of food products & & & & $0 \cdot 33$ & $0 \cdot 17$ & 0.05 & 0.33 & $0 \cdot 17$ & 0.06 \\
\hline Access to convenient means of public or private transportation & & & & 0.04 & $0 \cdot 17$ & 0.01 & 0.02 & $0 \cdot 17$ & 0.00 \\
\hline A short distance to your normal food shops & & & & $0 \cdot 32$ & $0 \cdot 16$ & $0 \cdot 05^{\star}$ & 0.24 & $0 \cdot 16$ & 0.04 \\
\hline $\begin{array}{l}\text { Appropriate kitchen appliances and equipment to make cooking } \\
\text { easier }\end{array}$ & & & & 0.55 & $0 \cdot 19$ & $0.08^{\star *}$ & 0.46 & $0 \cdot 19$ & $0 \cdot 06^{*}$ \\
\hline Access to organic food & & & & $0 \cdot 12$ & $0 \cdot 14$ & 0.02 & $0 \cdot 21$ & $0 \cdot 14$ & 0.04 \\
\hline Access to high-quality food products and brands & & & & 0.58 & $0 \cdot 18$ & $0.09^{\star \star}$ & 0.52 & $0 \cdot 18$ & $0.08^{\star *}$ \\
\hline $\begin{array}{l}\text { Sharing your meals with other people (including your partner or } \\
\text { spouse) }\end{array}$ & & & & 0.24 & $0 \cdot 15$ & 0.05 & $0 \cdot 12$ & $0 \cdot 17$ & 0.03 \\
\hline $\begin{array}{l}\text { Being able to receive support from authorities or private } \\
\text { organizations }\end{array}$ & & & & 0.02 & $0 \cdot 14$ & 0.00 & -0.04 & $0 \cdot 14$ & -0.01 \\
\hline $\begin{array}{l}\text { Having a neighbour or close friend who will help you when you } \\
\text { need it }\end{array}$ & & & & 0.30 & $0 \cdot 14$ & $0.06^{*}$ & 0.34 & $0 \cdot 13$ & $0.06^{*}$ \\
\hline Having members of your family who will help you when you need it & & & & $-0 \cdot 19$ & $0 \cdot 15$ & -0.03 & $-0 \cdot 18$ & $0 \cdot 15$ & -0.03 \\
\hline \multicolumn{10}{|l|}{ Goals } \\
\hline Keep your expenditures as low as possible & & & & & & & $0 \cdot 12$ & $0 \cdot 16$ & 0.02 \\
\hline Eat a healthy diet & & & & & & & $-0 \cdot 17$ & $0 \cdot 19$ & -0.02 \\
\hline $\begin{array}{l}\text { Choose food products and dishes that are quick and easy to } \\
\text { prepare }\end{array}$ & & & & & & & 0.04 & $0 \cdot 13$ & 0.01 \\
\hline Control your weight through your choice of food & & & & & & & $0 \cdot 38$ & $0 \cdot 14$ & $0 \cdot 08^{* *}$ \\
\hline Choose food products and dishes that you enjoy eating & & & & & & & $-0 \cdot 11$ & 0.22 & -0.01 \\
\hline Vary your menu and have a wide range of foods and dishes & & & & & & & 0.95 & $0 \cdot 20$ & $0 \cdot 13^{\star \star \star}$ \\
\hline Eat your meals in the company of other people & & & & & & & $-0 \cdot 11$ & $0 \cdot 16$ & -0.02 \\
\hline $\begin{array}{l}\text { Arrange shopping and preparation of meals so that you don't need } \\
\text { help from others }\end{array}$ & & & & & & & -0.03 & $0 \cdot 14$ & -0.01 \\
\hline $\begin{array}{l}\text { Maintain the cultural traditions of your country or region in relation } \\
\text { to food and meals }\end{array}$ & & & & & & & 0.09 & $0 \cdot 14$ & 0.02 \\
\hline Eat your daily meals in nice surroundings & & & & & & & -0.03 & $0 \cdot 20$ & -0.00 \\
\hline Be able to cook meals for others & & & & & & & 0.29 & $0 \cdot 14$ & $0 \cdot 06^{*}$ \\
\hline
\end{tabular}

$R^{2}=0.07$ for step $1 ; \Delta R^{2}=0.13$ for step $2 ; \Delta R^{2}=0.03$ for step 3 .

Coefficient was statistically significant: ${ }^{\star} P<0 \cdot 05,{ }^{\star \star} P<0 \cdot 01,{ }^{\star \star \star} P<0 \cdot 001$.

physical health affects variety of diet such that those who are in better health have a more varied diet. Finally, income affects variety of diet such that the higher the income the more the variety in the person's diet. As the $\beta$ coefficients of all the predictor variables are similar in value, this suggests that the sizes of the effects of living arrangements, car availability, physical health, mental health and monthly income on the variety of the diet consumed are roughly equal.

\section{Perceived resources and their influence on variety of diet}

Regression of varied eating $v$. the twenty-two perceived resource levels as the second step revealed that the increase in explained variance (change in $R^{2}=13 \%$ ) was significant $(F$ change $(22,1457)=10 \cdot 74, \quad P<0 \cdot 001)$. Good appetite $(\beta=0 \cdot 10, P<0 \cdot 001)$, food knowledge ( $\beta=0 \cdot 20, P<0 \cdot 001)$, access to convenient food products $(\beta=-0 \cdot 08, \quad P<0 \cdot 01)$, access to a good food service 
provider $(\beta=0 \cdot 15, P<0 \cdot 001)$, kitchen appliances $(\beta=$ $0 \cdot 08, P<0 \cdot 01)$, short distance to the shops $(\beta=0 \cdot 05$, $P<0 \cdot 05)$, access to high-quality products $(\beta=0.09$, $P<0.01)$ and support from friends and neighbours $(\beta=0.06, P<0.05)$ were shown to be significant predictors while good health, good dental health, cooking skills, mobility, ability to smell/taste, good income, low prices, access to new products, access to food storage, convenient transport, access to organic products, sharing meals with others, formal support and support from family were not seen as influencing a varied diet. This suggests that those who have a good appetite, a good knowledge of different foods and less access to convenient foods, but good access to a good service provider, have a more varied diet than those whose appetite is poor, whose food knowledge is low, have good access to convenient foods but do not have good access to a good service provider. In addition, those who have good kitchen appliances, good access to high-quality products, have a short distance to go to the shops and have the support of friends and neighbours have a more varied diet than those who think they are low on these resources. It is important to note that some of the perceived resources like income, access to transport, sharing meals and health may be insignificant here because the effects of these were already captured by related objective measures in the first step. Food knowledge, access to a good service provider and good appetite appear to be stronger predictors than the other five significant predictors.

\section{Influence of goals on variety of diet}

Regression of varied eating $v$. the eleven goals in the third step found that the increase in explained variance of $3 \%$ was significant $(F$ change $(11,1446)=4 \cdot 31, P<0 \cdot 001)$. Goals such as controlling weight $(\beta=0 \cdot 08, P<0 \cdot 01)$, having a variety of foods on the menu $(\beta=0 \cdot 13$, $P<0 \cdot 001)$ and cooking for others $(\beta=0 \cdot 06, P<0 \cdot 05)$ were significant predictors, whereas keeping expenditure low, eating a healthy diet, choosing convenient food, enjoying food and meals, eating in other's company, not receiving help, maintaining food culture and eating in a nice surrounding were found not to influence a varied food choice. This suggests that those who want to eat a varied diet or control their diet or cook for others eat a more varied diet than those who do not strive to achieve these goals. Of these goals, wanting to have a variety of foods on the menu was the best predictor of having a varied diet.

\section{Discussion}

Results showed that the actual resources older people have affect the quality of their diet in terms of how many different foods they eat. This is not surprising as we would expect people with more money to be able to afford a better quality and variety of food. These results confirm previous findings ${ }^{(13,23,42,43)}$. For example, Nord ${ }^{(42)}$ found that three-quarters of food-insecure elderly households obtained enough food to avoid hunger by eating a less varied diet. Banister and Bowling ${ }^{(19)}$ found that those older people able to travel by car to shops were able to buy and consume a wider range of food.

The impact of physical and mental health on dietary variety is also plausible, as those who are not in pain, have more energy and without emotional problems are more likely to eat a varied diet. This is in line with previous findings ${ }^{(14)}$ showing health to affect food-related behaviours. The finding that those who live alone eat a narrower diet than those living with a partner fits well with previous research ${ }^{(20)}$. Loneliness and lack of incentive to cook for one may contribute to why those who live alone eat a less varied diet. Studies have shown that eating with a television on or eating in a communal setting (e.g. community centres) widens the diet of those who live alone ${ }^{(44,45)}$.

In addition to the actual resources, perceived resources were found to influence older people's diets. Those who think they have a good appetite and know a lot about food were found to eat a more varied diet than those who said their appetite was poor or didn't know much about food. This suggests that increasing older people's food knowledge, by means such as information provision and cooking classes, may be a possible way to increase dietary variety. Increasing older people's access to a good service provider and improving their kitchen facilities are alternative means of increasing dietary variety. Sharpe et al. ${ }^{(13)}$ also found that lack of access to services such as meals on wheels served as a barrier to healthy eating for rural elderly.

Increasing access to high-quality meals was also found to increase older people's varied food intake, although access to organic foods or new products did not have significant effects. This suggests that older people's diets could be improved by providing good-quality foods that are familiar rather than new products and not necessarily organically grown.

In terms of social resources, having help from friends and neighbours rather than family increased the variety of older people's diets. This suggests that friends' and neighbours' help may be related to food insomuch as they may help with the shopping or taking the person to the shops, whereas help from family may be needed when there is illness or on more serious matters. Interestingly, while living with a partner did affect the quality of the diet, sharing meals with others did not contribute to a varied diet, suggesting that those who share meals with others eat the same range of foods as those who do not share meals with others.

The study also found that older people's food-related goals had an independent influence on their quality of diet over and above their actual and perceived resources. Unsurprisingly, those whose food-related goals include 
eating a varied diet ate a greater variety of foods than those who did not have this as a goal. Thus one way to change a narrow diet would be to find ways to influence older people to have this as one of their food-related goals, perhaps through information expounding the merits of a varied diet as well as examples of how to increase variety in a diet. In addition, those who wanted to cook for others also had a more varied diet than those who did not have this as a goal. Here too providing recipes and information to those who want to cook for others on how to increase the variety of foods used in their cooking can help. Surprisingly, those who wanted to control their weight also were found to have a more varied diet; similar results were demonstrated by Oaks and Slotterback ${ }^{(32)}$ where people's judgement of healthiness of food was influenced by whether or not they had dieting as a food-related goal. It could be argued that when trying to lose weight one needs to think more about what one eats and plan the meals carefully. This may give people the opportunity to think about the variety of foods they can eat, influencing their food intake. It could also be that when wanting to lose weight people have to learn more about foods in general and the increase in food knowledge may help to increase the types of foods they eat, as discussed earlier.

Taken together, the present results suggest that older people's variety of food intake does depend on resources such as their monthly income, whether they have access to a car, their living arrangement and their physical and mental health. However, in addition to these variables, the way older people perceive other resources such as their level of appetite, their food knowledge, their perception of the distance to the shops, access to highquality products, having better kitchen facilities, access to good service providers and support from their friends and neighbours all contribute to how varied a diet they eat. Further, older people's goals such as wanting to eat a varied diet, wanting to cook for others and wanting to control their weight also influence the variety in their diet.

The findings that perceived levels of resources and food-related goals impact on dietary variety gives additional means of possible interventions that can be used to encourage and influence older people's variety of diet. The results suggest that by encouraging older people to adopt certain food-related goals, such as wanting to eat a varied diet, wanting to cook for others or watching their weight, it would be possible to change their eating habits. Similarly, by increasing older people's food and nutrition knowledge it may be possible to increase dietary variety. A varied diet could also be fostered by making highquality products accessible to older people.

The study has a number of limitations. Food variety was measured using the weekly food variety score as it was easy to use across different countries. There are many other ways of measuring variety ${ }^{(46)}$. Future studies should compare how the different food variety measures square up against this one. There were only a limited number of indicators available for objective resources, and most resources were measured only as perceived by respondents. A more complete set of objective resource indicators could not only shed more light on the relationship between objective and perceived resources, but also aid in deriving implications for how older people's endowment with relevant resources can be improved. We should also note that responses to an inventory of selfreported resource items may be subject to halo effects. Future research should investigate the mechanisms through which these above-mentioned possible interventions influence dietary change. Further, additional food-related goals that may increase variety in older people's diet should be elicited and their effects studied in order to develop further intervention strategies and policies, resulting in a healthier elderly population.

\section{Acknowledgements}

Sources of funding: The study was carried out with financial support from the Commission of the European Communities, specific RTD programme 'Quality of Life and Management of Living Resources', QLK1-2002-02447, 'Choosing foods, eating meals: sustaining independence and quality of life in old age'. It does not necessarily reflect its views and in no way anticipates the Commission's future policy in this area. Preparation of this paper benefited also from a grant from the Danish Research Council, Programme Committee for Food and Health. Conflict of interest declaration: The authors have no conflicts of interest. Author contributions: M.D. - analysis and writing; M.R. and K.G.G. - design and editing; M.L. - design. Acknowledgements: The Food in Later Life Project Team comprises research scientists, interviewers, technicians, administrative staff and managers who continue to make the study possible. We are extremely grateful to all the representatives from day-care centres, local authorities, industry and professional bodies who took part.

\section{References}

1. Kinsella K \& Velkoff VA (2001) Health and Disability. An Aging World. US Census Bureau Series no. P95/01-1. Washington, DC: US Government Printing Office.

2. Wahlqvist ML, Kouris-Blazos A \& Hsa-Hage BH (1997) Aging, food, culture, and health. Southeast Asian J Trop Med Public Health 28, 100-112.

3. Wahlqvist ML, Kouris-Blazos A \& Wattanapenpaiboon N (1999) The significance of eating patterns: an elderly Greek case study. Appetite 32, 23-32.

4. Wahlqvist ML, Darmadi-Blackberry I, Kouris-Blazos A, Jolley D, Steen B, Lukito W \& Horie Y (2005) Does diet matter for survival in long-lived cultures? Asia Pac J Clin Nutr 14, 2-6.

5. Kennedy ET, Ohls J, Carlson S \& Fleming K (1995) The Healthy Eating Index: design and applications. J Am Diet Assoc 95, 1103-1108. 
6. Mozaffarian D, Kumanyika SK, Lemaitre RN, Olson JL, Burke GL \& Siscovick DS (2003) Cereal, fruit, and vegetable fibre intake and the risk of cardiovascular disease in elderly individuals. JAMA 289, 1659-1666.

7. Knoops KT, de Groot LC, Kromhout D, Perrin AE, MoreirasVarela O, Mentto A \& van Staveren WA (2004) Mediterranean diet, lifestyle factors, and 10-year mortality in elderly European men and women: the HALE project. JAMA 292, 1433-1439.

8. Song Y, Manson JE, Buring JE \& Liu S (2004) A prospective study of red meat consumption and type 2 diabetes in middle-aged and elderly women: The Women's Health Study. Diabetes Care 27, 2108-2115.

9. Trichopoulou A \& Critselis E (2004) Mediterranean diet and longevity. Eur J Cancer Prev 13, 453-456.

10. Hollis JH \& Henry JK (2007) Dietary variety and its effect on food intake of elderly adults. J Hum Nutr Diet 20, 345-351.

11. Bernstein MA, Tucker KL, Ryan ND, O'Neill EF, Clements KM, Nelson ME, Evans WJ \& Fiatarone Singh MA (2002) Higher dietary variety is associated with better nutritional status in frail elderly people. J Am Diet Assoc 102, 1096-1104.

12. Horwath C, Kouris-Blazos A, Savige G \& Wahlqvist ML (1999) Eating your way to a successful old age, with special reference to older women. Asia Pac J Clin Nutr 8, 216-225.

13. Sharpe DL, Huston SJ \& Finke MS (2003) Factors affecting nutritional adequacy among single elderly women. Fam Econ Nutr Rev 15, 74-82.

14. Hendy HM, Nelson GK \& Greco ME (1998) Social cognitive predictors of nutritional risk in rural elderly adults. Int $J$ Aging Hum Dev 47, 299-327.

15. Rolls BJ \& McDermott TM (1991) Effects of age on sensoryspecific satiety. Am J Clin Nutr 54, 988-996.

16. Westenhoefer J (2005) Age and gender dependent profile of food choice. In Diet Diversification and Health Promotion. Forum Nutrition, vol. 57, pp. 44-51 [I Elmadfe, editor]. Basel: Karger.

17. Fanelli MT \& Stevenhagen KJ (1985) Characterizing consumption patterns by frequency methodologies: core foods and variety of foods in diets of older Americans. $J \mathrm{Am}$ Diet Assoc 85, 1570-1576.

18. Duffy VB, Backstrand JR \& Ferris AM (1995) Olfactory dysfunction and related nutritional risk in free living, elderly women. J Am Diet Assoc 95, 879-884.

19. Banister D \& Bowling A (2004) Quality of life for the elderly: the transport dimension. Transport Policy 11, 105-115.

20. Sahyoun NR \& Zhang XL (2005) Dietary quality and social contact among a nationally representative sample of the older adult population in the United States. J Nutr Health Aging 9, 177-183.

21. Brown JL (1987) Hunger in the US. Sci Am 256, 37-41.

22. Sahyoun N \& Basiotis P (2001) Food insufficiency and the nutritional status of the elderly population. Fam Econ Nutr Rev 13, 58-60.

23. Blaylock J, Smallwood D, Kassel K, Variyam J \& Aldrich L (1999) Economics, food choices, and nutrition. Food Policy 24, 269-286.

24. Lee CJ, Templeton SB, Marlette M, Walker RS \& Fahm EG (1998) Diet quality and nutrient intakes of Black southern rural elderly. J Nutr Elder 17, 1-15.

25. Wallace DC, Pascarella MJ \& Campanella-Voica D (1997) Nutritional service use among rural elders. J Nutr Elder 16, $1-15$.

26. Shifflett PA \& McIntosh WA (1984) Influence of social support systems on dietary intake of the elderly. $J$ Nutr Elder 4, 5-18.

27. Walker D \& Beauchene RE (1991) The relationship of loneliness, social isolation, and physical health to dietary adequacy of independently living elderly. J Am Diet Assoc 91, 300-304.

28. Paquet C, St-Arnaud-McKenzie D, Ma ZF, Kergoat MJ, Ferland G \& Dube L (2008) More than just being alone: the number, nature, and complementarity of meal-time social interactions influence food intake in hospitalized elderly patients. Gerontologist 48, 603-611.

29. Revenson TA \& Johnson JL (1984) Social and demographic correlates of loneliness in later life. Am J Community Psychol 12, 71-85.

30. Baker AH \& Wardle J (2003) Sex differences in food choice: the contribution of health beliefs and dieting. Appetite $\mathbf{4 0}$, 269-275.

31. McDonald T \& Webster J 1998. Nutrition Information the Key to Better Diet, Better Health. USDA's Healthy Eating Index and Nutrition Information. Press Release no. 0209.98. http://www.usda.gov/cnpp/release_hei.html (accessed November 2007).

32. Oaks ME \& Slotterback CS (2002) The good, the bad, and the ugly: characteristics used by young, middle-aged and older men, women, dieters, and non-dieters to judge healthfulness of foods. Appetite 38, 91-97.

33. Wang WC, Worsley A \& Cunningham EG (2008) Social ideological influences on reported food consumption and BMI. Int J Behav Nutr Phys Act 5, 20.

34. Diener E \& Fujita F (1995) Resources, personal strivings, and subjective well-being: a nomothetic and idiographic approach. J Pers Soc Psychol 68, 926-935.

35. Dean MS, Grunert KG, Raats MM, Nielsen NA, Lumbers M \& Food in Later Life Project Team (2008) The impact of personal resources and their goal relevance on satisfaction with food related life among the elderly. Appetite 50, 308-315.

36. Savige GS, Hsu-Hage BH-H \& Wahlqvist ML (1997) Food variety as nutritional therapy. Curr Ther March, 57-67.

37. Hodgson JM, Hsu-Hage BHH \& Wahlqvist ML (1994) Food variety as a quantitative descriptor of food intake. Ecol Food Nutr 32, 137-148.

38. Hodgson JM, Hage B, Wahlqvist ML, Kouris-Blazos A \& Lo CS (1991) Development of two food variety scores as measures for the prediction of health outcomes. Proc Nutr Soc Aust 16, 62-65.

39. Wahlqvist ML, Lo CS \& Myers KA (1989) Food variety is associated with less macrovascular disease in those with type II diabetes and their healthy controls. J Am Coll Nutr $\mathbf{8}$, $515-523$.

40. Ogle BM, Hung PH \& Tuyet HT (2001) Significance of wild vegetables in micronutrient intakes of women in Vietnam: an analysis of food variety. Asia Pac J Clin Nutr 10, 21-30.

41. Ware JE, Kosinski M, Dewey JE \& Gandek B (2001) How to Score and Interpret Single-Item Health Status Measures: A Manual for Users of the SF- ${ }^{T M}$ Health Survey. Lincoln, RI: QualityMetric Incorporated.

42. Nord M (2002) Measuring the food security of elderly persons. Fam Econ Nutr Rev 15, 33-46.

43. Quinn ME, Johnson MA, Poon LW, Martin P \& NickolsRichardson SM (1997) Factors of nutritional health-seeking behaviors: findings from the Georgia Centenarian study. J Aging Health 9, 90-104.

44. De Castro JM (2002) Age-related changes in the social, psychological, and temporal influences in food intake in free-living, healthy, adult humans. J Gerontol A Biol Sci Med Sci 57, 368-377.

45. Stroebele N \& de Castro JM (2004) Effect of ambience on food intake and food choice. Nutrition 20, 821-838.

46. Arvaniti F \& Panagiotakos DB (2008) Healthy indexes in public health practice and research: a review. Crit Rev Food Sci Nutr 48, 317-327. 